\title{
A pós-graduação e o estudo das relações entre habilidades metalinguísticas e linguagem escrita
}

\section{Postgraduate studies and the studies of the relationship between metalinguistic skills and written language}

\author{
Ellen Michelle Barbosa de Moura* \\ Secretaria de Educação do Distrito Federal - (SEDF), Distrito Federal, Brasília, \\ Brasil.
}

\author{
Fraulein Vidigal de Paula** \\ Universidade de São Paulo - USP, São Paulo, São Paulo, Brasil.
}

\begin{abstract}
RESUMO
A pós-graduação no país tem um papel fundamental na formação de pesquisadores e na geração de pesquisas e conhecimentos novos a respeito da temática metalinguística e alfabetização. Nesse sentido, o objetivo do presente artigo foi mapear a produção acadêmica brasileira sobre desenvolvimento metalinguístico e linguagem escrita, no período de 2005 a 2010, em dissertações e teses. Para este levantamento, foi consultado o banco de teses da CAPES. Os resultados foram organizados conforme o nível da pós-graduação, área de concentração, estado, universidade, termoschave, características e número de sujeitos investigados, delineamento da pesquisa e ano de defesa. Constatou-se que a produção anual dobrou neste período, somando 187 estudos produzidos nestes cinco anos. Porém, o aumento quantitativo não foi acompanhado, em igual medida, pela diversificação no tipo de delineamento, faixa etária dos sujeitos e das habilidades metalinguísticas investigadas. Os resultados são discutidos em termos de avanços, limitações e tendências para novos estudos.
\end{abstract}

Palavras-chave: Escrita, Alfabetização, Metalinguagem, Revisão.

\begin{abstract}
The postgraduate education in the country has a key role in training researchers and the generation of new knowledge and research on the theme metalinguistic and literacy. In this sense, the purpose of this paper was to map the Brazilian academic production on metalinguistic development and written language in the period 2005 to 2010, in dissertations and theses. For this survey, we consulted the CAPES thesis database, as a primary source. The results were organized according to the level of postgraduate studies, concentration area, state, university, key terms, features and number of subjects investigated, the research design and years of defense. It was found that the annual production doubled in this period, totaling 187 studies produced in these five years. However, the quantitative increase was not matched in equal measure by diversifying the type of design, age of the subjects investigated and metalinguistic skills. The
\end{abstract}


results are discussed in terms of advances, limitations and trends for further studies.

Keywords: Written, Literacy, Metalanguage, Review.

\section{I ntrodução}

Qual o papel das habilidades metalinguísticas na aprendizagem de uma língua escrita, como o português? Uma forma de responder a esta questão, do ponto de vista da psicologia cognitiva, seria considerar que tudo começa pela identificação de regularidades percebidas nas palavras e textos. Mesmo crianças de pouca idade aprendem a extrair conhecimentos sobre o que é saliente na língua tanto oral quanto escrita. Na escrita, a presença de letras, a direção do texto da esquerda para a direita, dentre outros aspectos, que se tornam evocados automaticamente no encontro com a palavra escrita (Gombert, 1990). Isto pode acontecer em práticas de letramento, quando a criança se depara frequentemente com uma palavra e extrai regularidades a seu respeito, tais como pronúncia, grafia, significados. Além disto, a oportunidade de pensar sobre o uso que faz da linguagem oral e de seu conhecimento emergente a respeito da escrita, favorecerá o desenvolvimento de outros níveis de elaboração de seu conhecimento linguístico. Trata-se de aprendizagens que envolvem deliberação, elaboração verbal e reflexão sobre o conhecimento que se está adquirindo, ou seja, de habilidades metalinguísticas (GOMBERT, 2003).

Comparando as atividades de uso da linguagem quanto à necessidade de ativação desses diferentes níveis de controle, abstração e elaboração da estrutura formal da língua, as atividades de leitura e de escrita exigem controle mais explícito e deliberado do que a expressão oral, em boa parte das ocasiões. Já o ato de escrever, por ser uma atividade predominantemente de produção, exigiria um nível mais elevado de ativação de habilidades metalinguísticas do que na leitura, na qual predominam processos de reconhecimento. Porém, tanto no ato de ler quanto de escrever, diferentes conhecimentos devem ser coordenados para sua realização proficiente. Há evidências de que quanto mais meta o conhecimento sobre diversos aspectos da linguagem, mais estes se tornam correlacionados entre si e com as habilidades de leitura e de escrita (PAULA; CORREA; SPINI LLO, 2012; PAULA, 2007).

Em leitura, as habilidades meta possibilitam controle deliberado do produto dos processos automáticos, cada vez mais facilmente, porém nunca sem esforço e 'custo' cognitivo, segundo Gombert (2003). Estes seriam adequados para, por exemplo, tratar corretamente ortografias minoritárias, aplicar regras de concordância a despeito da ortografia automaticamente ativada com base na frequência das 
configurações, em um leitor proficiente. As habilidades metassintáticas, permitem, por exemplo, que o leitor/escritor conceba a concordância de vários termos na frase, especialmente em construções menos canônicas, além do reconhecimento e compreensão de palavras em contextos que exigem tomada de decisão para redução de ambiguidade semântica e interpretativa, da palavra ou sentença.

Diferentemente, em um leitor e escritor principiante, as funções meta permitiriam a compreensão do funcionamento da língua e a ampliação da pouca qualidade e variedade de conhecimentos disponíveis, que não permitem ainda muitas aprendizagens implícitas. As habilidades metalinguísticas, na concepção da psicologia, envolvem uma reflexão consciente, na medida em que o indivíduo focaliza sua atenção na linguagem e pensa sobre ela, sendo capaz de manipular deliberadamente seus diferentes aspectos, tais como: as unidades sonoras da língua (consciência fonológica), as palavras como unidades de significado e ortografia independentes na língua (consciência lexical), as unidades mínimas de significado na língua que compõem as palavras, bem como os seus processos de formação a partir dos morfemas (consciência morfológica), a estrutura gramatical das sentenças (consciência sintática), o uso e reflexão intencional sobre alguns processos de formação das palavras, suas flexões, suas funções e relações nas frases, em que a morfologia e a sintaxe não se afiguram como níveis independentes de organização da linguagem (consciência morfossintática), a estrutura e aspectos pragmáticos de textos de diferentes gêneros (consciência textual ou metatextual) (HERRIMAN, 1986; NESDALE; TUNMER, 1984; GOMBERT, 1990; CARLISLE, 1995; BARRERA; MALUF, 2003; SPINILLO; SIMÕES, 2003; BARRERA， 2003， CORREA， 2005; GUIMARÃES; PAULA, 2010). Estas se diferenciam das habilidades linguísticas, acionadas de modo tácito e automático pelo uso da língua como meio de expressão e comunicação, por exemplo.

A temática do desenvolvimento metalinguístico é historicamente nova, pois são da década de 1980 os primeiros estudos no campo da psicologia cognitiva e ainda assim, somente nos anos 1990 é que ela começa a ganhar lugar de importância e destaque nas discussões sobre alfabetização, tema em ascensão dada a produção crescente sobre o mesmo. Estudos em diversas línguas e a respeito do português brasileiro atestam que o desenvolvimento das habilidades metalinguísticas está relacionado ao desenvolvimento das habilidades de leitura e de escrita, logo, ao processo formal de alfabetização (GOMBERT, 2003; BARRERA; MALUF, 1987; CAPELLINI; CIASCA, 2000; DEACON; KIRBY, 2004; CARDOSO-MARTINS; SILVA, 2008; dentre outros).

No Brasil, os estudos a esse respeito se desenvolveram de modo mais expressivo a partir do final da década de 90 do século passado, tal 
como demonstrado no estudo de revisão de Maluf, Zanella e Pagnez (2006), a respeito da produção publicada em dissertações, teses e artigos científicos entre os anos de 1987 e 2005 . Segundo as autoras, foram localizados 157 estudos, com aumento progressivo ao longo dos anos. Identificaram que a habilidade metalinguística mais estudada até então foi a consciência fonológica, com predomínio de estudos transversais no início da alfabetização. Identificaram um descompasso entre a quantidade de trabalhos defendidos no nível da pós-graduação e a quantidade bem menor de estudos publicados em artigos científicos.

Segundo Hutz, Rocha, Spink e Menandro (2010), a produção de artigos científicos tem-se ampliado na área nos últimos dois triênios, mais do que a de livros e capítulos, o que atribuem ao aperfeiçoamento da qualidade dos periódicos nacionais e à internacionalização crescente da produção nesta área. A proporção teses e dissertações defendidas / artigos, livros publicados é tomada como um indicador da qualidade dos programas de pós-graduação, pois reflete o quanto do investimento em pesquisa tranformou 0 campo da divulgação do conhecimento aos pares e sociedade em geral.

Hagen, Miranda e Mota (2010) investigaram a produção de artigos científicos com relato de estudos empíricos sobre a consciência morfológica e alfabetização, em revistas nacionais e internacionais de seletiva política editorial. Identificaram poucos artigos brasileiros a respeito deste tema e muitas questões em aberto. Destacam a necessidade de estudos que investiguem as relações causais entre essas duas variáveis, bem como as aplicações educacionais das descobertas acerca do desenvolvimento desta habilidade metalinguística.

Lembrando que a pós-graduação brasileira completou quarenta anos recentemente, Severino (2009) enfatiza o papel substantivo da pósgraduação na produção da pesquisa e na formação de pesquisadores para avanço do conhecimento científico criativo, crítico, novo e relevante. Ainda que os artigos alcancem maior visibilidade na comunidade científica, observar a publicação de dissertações e teses sobre habilidades metalinguísticas e linguagem escrita pode ser um indicador importante da formação de pesquisadores neste campo, do conhecimento produzido e que deverá ser potencializado em outras formas de publicação posteriormente.

Em termos de políticas públicas para a expansão dos centros de pesquisa no país, pode ser importante localizar onde se concentram as pesquisas e pesquisadores sobre as habilidades metalinguísticas e os processos de ensino e aprendizagem da leitura e da escrita, bem como as regiões onde este tema é menos investigado. Este mapeamento pode ser pensado, por exemplo, em termos da distribuição desigual do analfabetismo (BRASIL, 2003; 2010). O 
entendimento dessa temática envolve conhecimentos psicológicos, linguísticos, fonoaudiológicos e educacionais, o que sugere a possibilidade de encontrar trabalhos acadêmicos defendidos em programas de pós-graduação nestas diferentes áreas a respeito da mesma.

A importância de estudos de revisão reside, portanto, na sua contribuição para entender a evolução do campo de estudos, avanços, carências, tendências e perspectivas(Maluf, Zanella e Pagnez (2006) ; Hagen, Miranda e Mota 2010).

Neste sentido, o objetivo do presente artigo foi mapear a produção acadêmica brasileira sobre habilidades metalinguísticas e linguagem escrita, no período de 2005 a 2010, em dissertações e teses brasileiras.

\section{Método}

\subsection{Bases consultadas e procedimento de coleta de dados}

Como fonte primária para a localização das dissertações e teses, defendidas em programas de pós-graduação no Brasil no período de 2005 a 2010, a respeito do tema desenvolvimento metalinguístico e linguagem escrita, foi consultado o Banco de teses disponível no Portal da Coordenação de Aperfeiçoamento de Pessoal de Nível Superior - CAPES, através do site $<$ http://capesdw.capes.gov.br/capesdw/>. O Portal de periódicos CAPES, no qual está contido o Banco de teses, é uma biblioteca virtual que reúne e disponibiliza o acesso à diferentes modalidades de publicação de informações científicas nacionais e internacionais de alto nível a instituições de ensino e pesquisa brasileiras.

O Banco de teses é anualmente atualizado através da importação de dados disponíveis nas bibliotecas digitais de dissertações e teses das universidades brasileiras. São os programas de pós-graduação que disponibilizam os resumos das dissertações e teses e se responsabilizam pela veracidade das informações. Estes podem ser pesquisados nesta base por autor, assunto (palavra chave), instituição, nível e ano.

Os dados foram coletados a partir do acesso realizado nas datas: 04 de novembro de 2010, quando ainda não haviam sido disponibilizados os trabalhos defendidos em 2010 e nos dias 10 de março e 10 de abril de 2012, dias em que aconteceu a coleta da produção referente ao ano de 2010.

Os dados analisados neste artigo foram extraídos dos termos-chave e resumo das teses e dissertações. Foram contabilizados estudos realizados sobre a leitura e escrita em português brasileiro. Seis destes estudos comparam habilidades do português e em uma 
segunda língua. As obras divulgadas que apareceram relacionadas mais de uma vez, em virtude das palavras-chave utilizadas para o levantamento, foram contabilizadas uma única vez. Todavia, foram excluídos os trabalhos que apareceram no levantamento via termochave, mas que pela leitura do resumo constatou-se que não tinham relação com a temática em questão (a exemplo, estudos de literatura, biologia e línguas indígenas).

\subsection{Termos chave utilizados no levantamento}

A busca por assunto, opção 'todas as palavras' foi norteada pela utilização dos mesmos indexadores adotados na pesquisa de Maluf, Zanella e Pagnez (2006), acrescido dos termos desenvolvimento metalinguístico e habilidades metalinguísticas que apareceram nas produções levantadas, sendo eles:

- Consciência, conjuntamente com as especificações: Fonológica, Lexical, Metalinguística, Metafonológica, Metatextual, Morfológica, Morfossintática, Ortográfica, Semântica, Sintática.

- Habilidade, variando os termos: Fonológica, Lexical, Metalinguística, Metafonológica, Metatextual, Morfológica, Morfossintática, Ortográfica, Semântica, Sintática.

- E também os termos: Fonologia e Alfabetização; e as combinações alternadas entre os termos Alfabetização; Leitura e escrita com Metalinguagem, Desenvolvimento metalinguístico, Metalinguística e Habilidades metalinguísticas.

Foi realizado o cruzamento desses indexadores, para localizar estudos que investigaram mais de uma habilidade metalinguística.

Ao final deste levantamento, foi localizado o total de 350 trabalhos de teses e dissertações considerando as repetições, dos quais 187 (sem repetição) foram classificados e analisados conforme as seguintes categorias: nível da pós-graduação; ano da defesa; estado; universidade de origem; termos-chave; delineamento; área do conhecimento; sujeitos investigados quanto à tipicidade, faixa etária, tamanho da amostra e tipo de instituição de acesso aos sujeitos.

\section{Resultados e Discussão}

Quanto ao nível da pós-graduação, dos 187 trabalhos encontrados, 47 eram teses de doutorado e 140 dissertações de mestrado no período. 


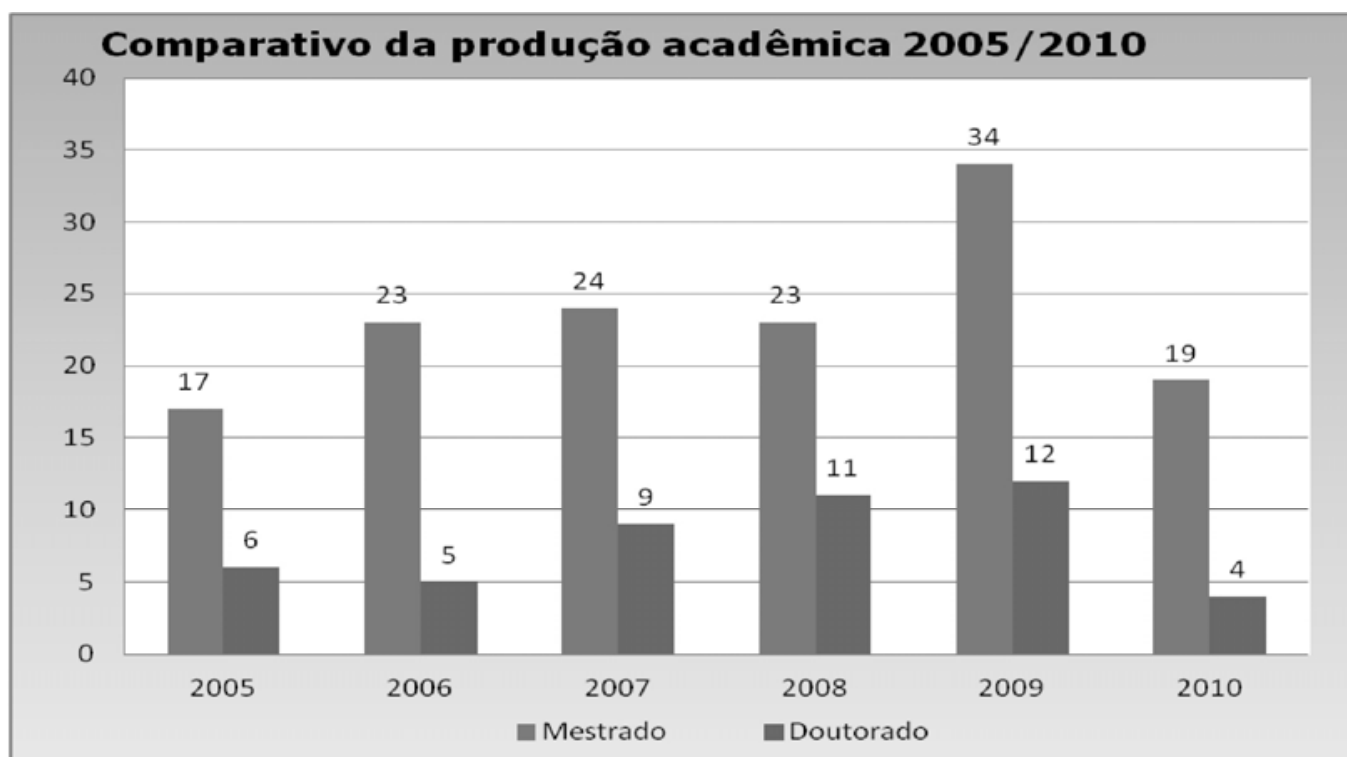

Figura 1: Dissertações de mestrado e teses de doutorado conforme o ano de defesa.

Ao comparar as defesas efetuadas em 2005 e em 2009, constata-se que a produção anual dobrou neste período, tanto em número de teses, quando de dissertações defendidas (Figura 1), mas que no ano de 2010 houve nova diminuição, provavelmente, por não estarem todos dos trabalhos concluídos informados a contento nos sites das universidades, quando da coleta realizada pelo banco de teses CAPES. Outro fator importante a salientar é que as dissertações de mestrado aparecem em maior número em todos os anos, tendo em vista de que é pré-condição e costuma ser realizado na metade do tempo do doutorado. Além disto, parte dos programas de pósgraduação oferece apenas a formação no nível de mestrado. 


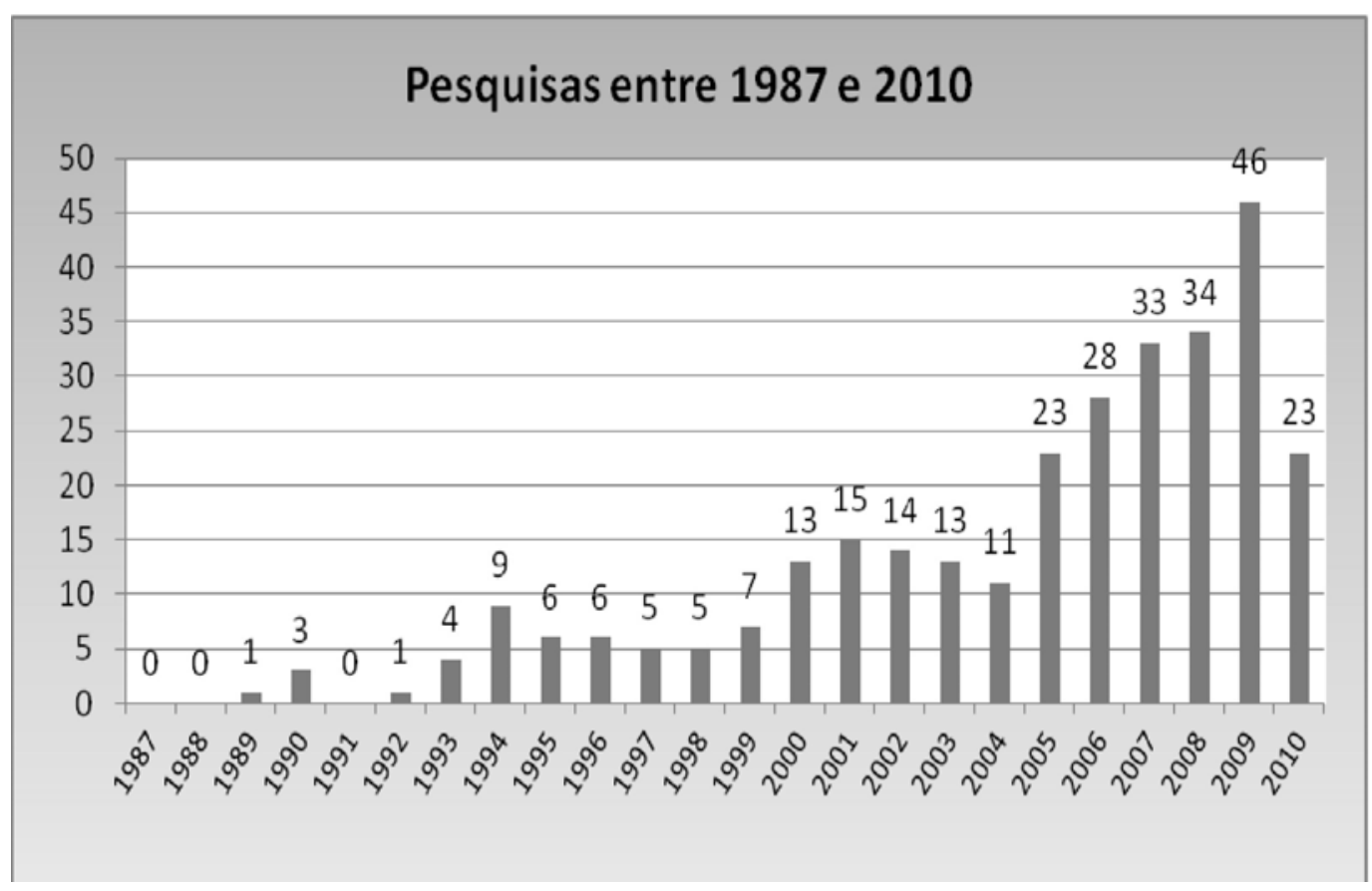

Figura 2: Análise geral do número de trabalhos, incluindo os do estudo de Maluf, Zanella e Pagnez (2006).

Porém, ao se comparar os dados apresentados na revisão de Maluf, Zanella e Pagnez (2006) com os dados dos anos subsequentes (Figura 2), observa-se que em 19 anos, no período de 1987 a 2005, foram defendidos 157 trabalhos sobre a temática em questão nos programas de pós-graduação credenciados, enquanto que nos cinco anos seguintes foram defendidos 187 trabalhos, ou seja, houve um crescimento importante do interesse por essa temática, o que deve também refletir o maior número de pesquisadores da mesma que ingressaram nos programas de pós-graduação nos últimos anos como orientadores. No ano de 2010 acontece uma diminuição das pesquisas defendidas. As hipóteses possíveis para esse acontecimento são que os dados ainda podem não estar disponibilizados em sua totalidade. 


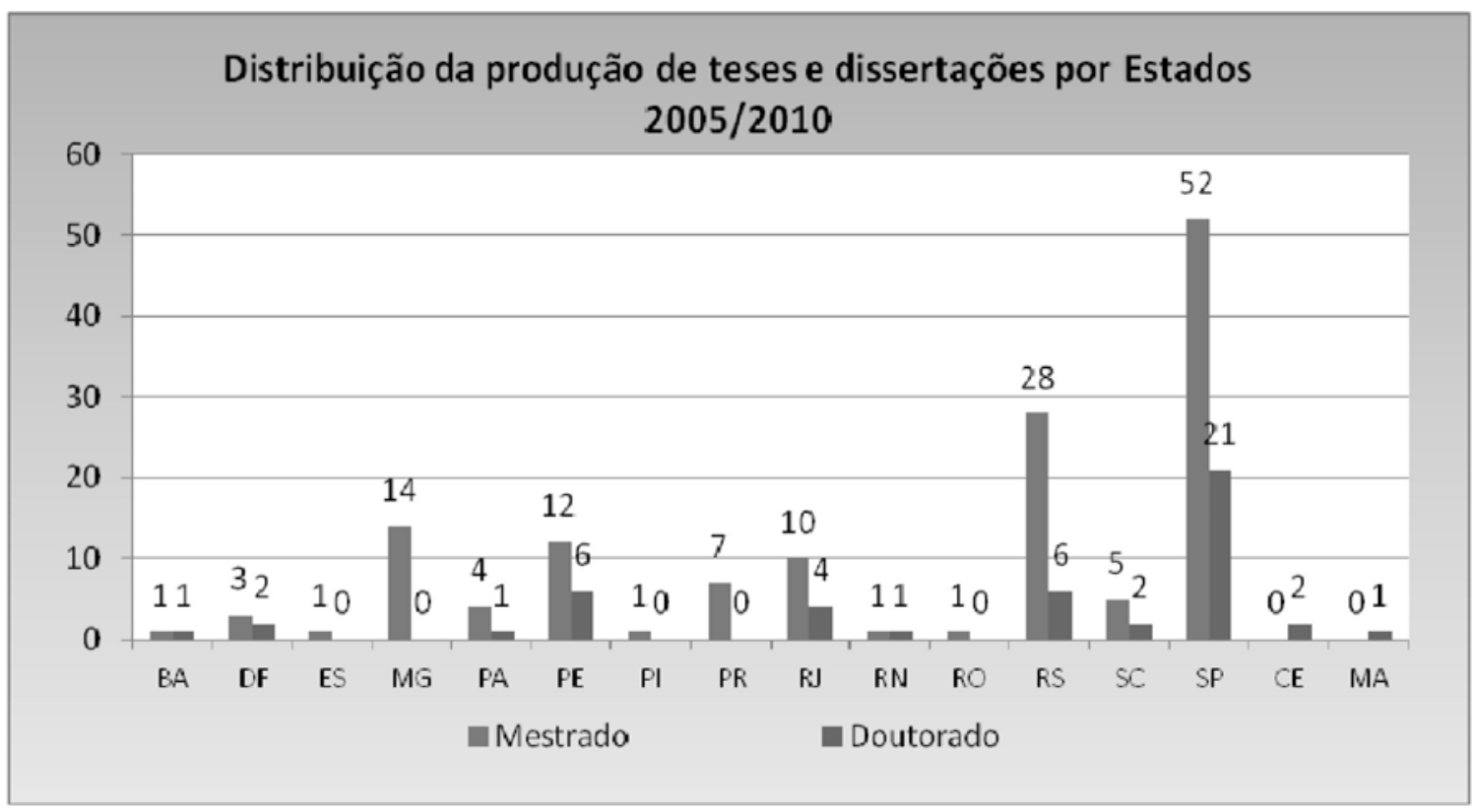

Figura 3: Distribuição das teses e dissertações por estados entre 2005 e 2010.

Identificou-se a pertinência de analisar em conjunto os dados referentes à produção por estados da Federação e por universidade, em parte por se considerar a distribuição desproporcional do número de universidades por região e por estados (Figura 3 e Tabela 1).

Tabela 1: Distribuição das teses e dissertações por universidades entre 2005 e 2010.

\begin{tabular}{|c|c|c|c|}
\hline Universidades & Mestr. & Dout. & Total \\
\hline USP & 20 & 12 & 32 \\
\hline UFPE & 12 & 6 & 18 \\
\hline PUC RS & 11 & 3 & 14 \\
\hline UFSM & 12 & 1 & 13 \\
\hline UFMG & 12 & $\mathbf{0}$ & 12 \\
\hline PUC SP & 7 & 4 & 11 \\
\hline UFRJ & 5 & 4 & 9 \\
\hline UNESP & 7 & 2 & 9 \\
\hline MACKENZIE & 8 & $\mathbf{0}$ & 8 \\
\hline UFPA; UFPR & 4 & $\mathbf{0}$ & 8 \\
\hline Un B; USF - SÃO FRANCISCO & 2 & 2 & 8 \\
\hline UFSC & 1 & 2 & 3 \\
\hline UNIFESP & 5 & 1 & 6 \\
\hline UNISC & 3 & $\mathbf{0}$ & 3 \\
\hline UVA & 4 & $\mathbf{0}$ & 4 \\
\hline UEM & 2 & $\mathbf{0}$ & 2 \\
\hline UFCE & $\mathbf{0}$ & 2 & 2 \\
\hline UFRN & 1 & 1 & 2 \\
\hline UFRS & 1 & $\mathbf{1}$ & 2 \\
\hline UFSCAR & 3 & $\mathbf{1}$ & 4 \\
\hline PUC BRASIUAA; PUC PR, PUC RJ & 1 & $\mathbf{0}$ & 3 \\
\hline UFAL; UFPA & $\mathbf{0}$ & 1 & 2 \\
\hline UFBA & $\mathbf{1}$ & $\mathbf{1}$ & 2 \\
\hline UFJF & 2 & $\mathbf{0}$ & 2 \\
\hline \multicolumn{4}{|l|}{$\begin{array}{l}\text { UFPI; UNIR; UniRitter;UNISUL; } \\
\text { Un ivali; UNIUI;; UFES; }\end{array}$} \\
\hline UPF(Passo Fundo) & 1 & $\mathbf{0}$ & 8 \\
\hline
\end{tabular}


Observando a distribuição das teses e dissertações por universidades entre 2005 e 2010, destacam-se nos primeiros lugares a Universidade de São Paulo, com 32 trabalhos e a Universidade Federal de Pernambuco, com 18 trabalhos defendidos. Em uma análise por estado, tem-se que a produção está concentrada principalmente em universidades do estados de São Paulo $(N=70$, somando-se a produção de cinco universidades) e do Rio Grande do Sul ( $N=29$, somando-se a produção de três universidades). Já Pernambuco $(N=18)$, Rio de Janeiro $(N=16)$ e Minas Gerais $(N=14)$, apesar de terem menos universidades que lidam com o tema, seus pesquisadores têm uma produção expressiva em orientar trabalhos na área (Figura 4 e Tabela 1). E ainda, essa concentração está sobretudo na região Sudeste, já que se somarmos a produção dos estados de São Paulo $(\mathrm{N}=70)$, Rio de Janeiro $(\mathrm{N}=16)$ e Minas Gerais $(\mathrm{N}=14)$ temos 100 trabalhos, em um total de 187.

Vale ressaltar, que de um modo geral, ainda temos uma distribuição bastante desigual do número de universidades com produção em pesquisa entre as diferentes regiões do país. Se se contabilizar apenas as federais, estas estão em maior número na região Sudeste, Nordeste, e Sul, e menor nas regiões Norte e Centro-Oeste. (CHIARINI; VIEIRA; ZORZIN, 2012).

Outro fator a se considerar são problemas relacionados à qualidade do processo de alfabetização, sobretudo no sistema público de ensino, no país como um todo. Mas nos estados em que se configuram os maiores índices de analfabetismo, como Alagoas, Piauí e Paraíba (BRASIL, 2010), constata-se da inexistência a pouquíssimos trabalhos defendidos sobre a relação entre habilidades metalinguíticas e alfabetização, embora não tenha sido controlado se há dissertações e teses a respeito da temática metalinguagem e alfabetização com estudantes de escolas destes estados. Isto pode estar relacionado a um menor investimento em educação de um modo mais amplo, abarcando tanto o investimento na qualidade do sistema de ensino obrigatório, quanto no ensino superior e na produção de conhecimento científico a respeito. Este aspecto pode ser revelador de outras desigualdades históricas, de natureza populacional, socio-econômica, por exemplo, a serem mais bem exploradas em estudos futuros.

Tabela 2: Trabalhos encontrados por termo chave. 


\begin{tabular}{|c|c|c|c|c|}
\hline Termos-chave & Mest. & Dout. & Soma & $\%$ \\
\hline Consciência fonológica & 74 & 13 & 87 & $46,52 \%$ \\
\hline Consciência lexical & 1 & 3 & 4 & $2,14 \%$ \\
\hline Consciência metalinguística & 11 & 3 & 14 & $7,49 \%$ \\
\hline Consciência metatextual & 3 & 1 & 4 & $2,14 \%$ \\
\hline Consciência morfológica & 2 & 2 & 4 & $2,14 \%$ \\
\hline Consciência morfossintática & 1 & 1 & 2 & $1,07 \%$ \\
\hline Consciência ortográfica & 8 & 5 & 13 & $6,95 \%$ \\
\hline Consciência semântica & 2 & 2 & 4 & $2,14 \%$ \\
\hline Consciência sintática & 2 & 2 & 4 & $2,14 \%$ \\
\hline Fonologia e alfabetização & 23 & 9 & 32 & $17,11 \%$ \\
\hline Habilidade fonológica & 11 & 4 & 15 & $8,02 \%$ \\
\hline Metalinguagem e alfabetização & 0 & 1 & 1 & $0,53 \%$ \\
\hline Metalinguagem leitura e escrita & 1 & 0 & 1 & $0,53 \%$ \\
\hline Metalinguística e alfab & 1 & 1 & 2 & $1,07 \%$ \\
\hline Total & 140 & 47 & 187 & $100,00 \%$ \\
\hline
\end{tabular}

Não é por acaso que dentre as habilidades e conhecimentos metalinguísticos, a dimensão mais estudada na nossa língua é a dimensão fonológica. É essencial para um aprendiz do português brasileiro, sobretudo no início do processo de alfabetização, tomar consciência e compreender o princípio fonográfico ou alfabético de que a escrita é um sistema de representação dos sons da fala por meio de unidades gráficas - as letras. (CAPOVILLA, A.; CAPOVILLA, F., 2000; CARDOSO-MARTINS; BATISTA, 2005; CARDOSO-MARTINS, 1995; CORREA; CARDOSO-MARTINS; RODRIGUES, 2010; MALUF, BARRERA, 1997).

No entanto, vários aspectos do desenvolvimento metalinguístico precisam ser considerados para a compreensão das habilidades envolvidas na leitura e escrita (ortografia) do português brasileiro (e.g., GUIMARÃES, PAULA, 2010; MOTA, 2009; PAULA, CORREA; SPINI LLO, 2012; SALLES; JOU; STEI N, 2007).

Neste sentido, observou-se que os trabalhos que enfatizaram somente um aspecto da Metalinguística foram 99, sendo que desse total, 60 estudaram apenas a consciência fonológica. Que enfatizaram dois aspectos da Metalinguística foram 53. Sendo que desse total, 41 estudaram também a consciência fonológica. Os trabalhos que enfatizaram três aspectos da Metalinguística foram 16, sendo que desse total, 13 estudaram a consciência fonológica. Os trabalhos que enfatizaram quatro aspectos da Metalinguística foram 10, sendo que 
desse total, sete estudaram a consciência fonológica. Os trabalhos que enfatizaram cinco aspectos da Metalinguística foram três, sendo que todos estudaram a consciência fonológica. Os trabalhos que enfatizaram seis aspectos da Metalinguística foram dois, sendo que todos estudaram a consciência fonológica e os que estudaram sete foram quatro e todos incluíram a consciência fonológica.

Somente quatro trabalhos enfatizaram sete aspectos da Metalinguagem, sendo que estes estudaram também a consciência fonológica.

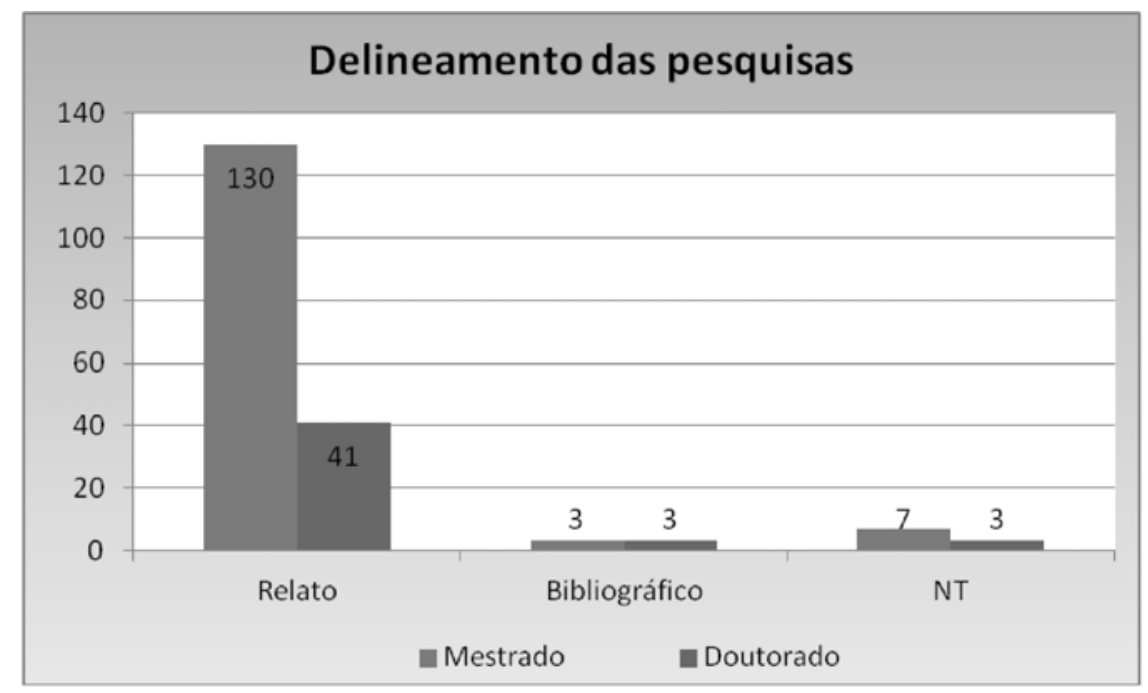

Figura 4: Quanto aos tipos de pesquisa.

A maioria dos trabalhos pesquisados apresenta como forma de estudo - relato de pesquisa, que conforme apresentado nos resumos, envolvem o uso de tarefas de avaliação de habilidades cognitivas, linguísticas e metalínguístas, em contexto escolar, a maioria caracterizado de modo mais ou menos explícito, estudos do tipo transversal e correlacional. Aproximadamente $25 \%$ dos trabalhos descrevem a distribuição dos sujeitos em dois grupos, sendo um de controle e outro que apresenta alguma dificuldade de aprendizagem relacionada com a leitura e escrita. Uma parte menor destes explicita ou sugere o uso de intervenção com grupo experimental, principalmente nas areas de psicologia e fonoaudiologia. Observa-se uma diferença interessante em relação aos estudos na área de educação, em que o principal meio de pesquisa é a observação direta de salas de aula.

Para uma análise mais aprofundada dos aspectos metodológicos das pesquisas, torna-se necessário um aprofundamento no estudo destes trabalhos, em termos do tipo de instrumentos utilizados, relação objetivo, pressupostos teóricos, tipo de instrumentos e procedimentos adotados, resultados encontrados e natureza das discussões e conclusões. Sugere-se a condução de estudos de revisão 
com uso de recursos de metanálise mais refinados e de análises estatísticas inferenciais, que foquem e se aprofundem nestes aspectos mais específicos, a exemplo do estudo de Correa (2005).

No presente artigo, parte da análise destes aspectos também ficou compromentida pela falta de uniformidade do tipo de informação sobre a dissertação ou tese, veiculada tanto nos títulos quanto nos resumos e palavras-chave.

Tabela 3: Área de conhecimento na pós-graduação em que as pesquisas foram desenvolvidas.

\begin{tabular}{lrr}
\multicolumn{1}{c}{ Área de conhecimento } & Mestr. & Dout. \\
\hline Ciências da linguagem & $\mathbf{1}$ & $\mathbf{0}$ \\
Ciências da saúde & $\mathbf{1}$ & $\mathbf{1}$ \\
Educação & 37 & 9 \\
Fonoaudio logia & 21 & 4 \\
Letras & $\mathbf{9}$ & 3 \\
\hline Letras e linquística & 5 & 3 \\
Língua Portuguesa & 0 & 1 \\
Linguística & 10 & 8 \\
Linguística e língua portuguesa & 1 & 1 \\
Linguística e psicolinguística & 1 & 0 \\
Música & 1 & 0 \\
Psicologia & 54 & 17
\end{tabular}

A análise da figura 4 e da tabela 3 tabela acima se percebe que a maioria dos trabalhos é de relatos de pesquisa. E que as áreas de conhecimento que mais se dedicam aos estudos da metalinguagem são a psicologia (71) educação (46) e a fonoaudiologia (25). Mas se tomarmos em conjunto os programas ciências da linguagem, de letras e linguística em suas variações, este somam 43 trabalhos defendidos. Tal constatação nos remete à necessidade de atentar para a provável polissemia dos conceitos de habilidades metalinguísticas, e mesmo de leitura e escrita, envolvidos nos trabalhos defendidos nestas diferentes áreas, o que merece um estudo de cunho teórico reflexivo, dialogado entre representantes destas diferentes áreas. 


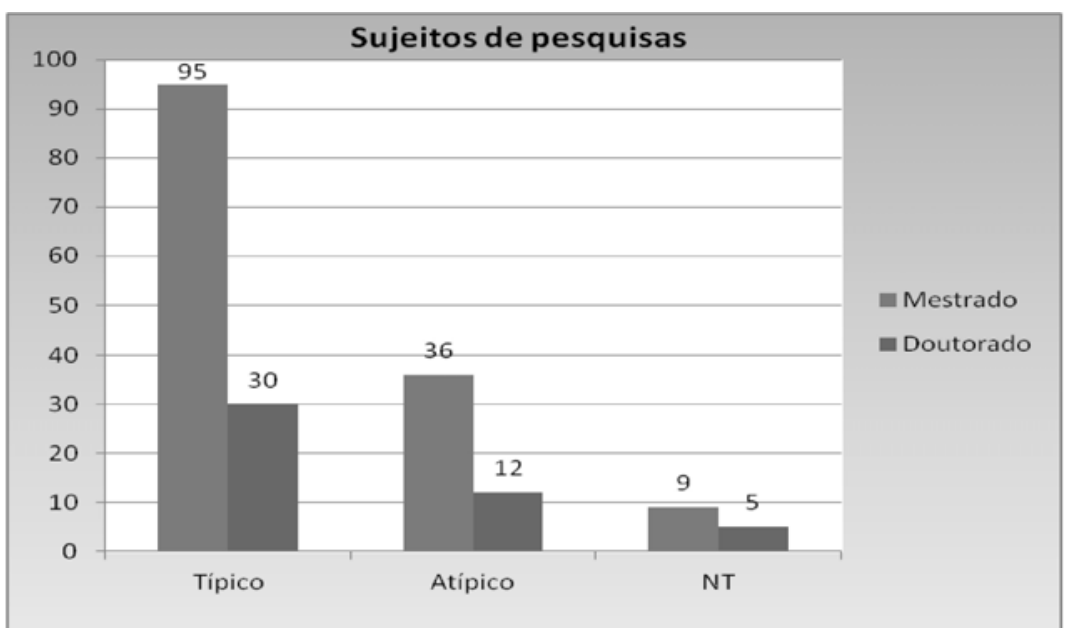

Figura 5: Sujeitos, quanto à tipicidade.

Ao se analisar a figura 5 fica claro que o perfil é de sujeitos típicos e que o percentual de dissertações e teses que pesquisaram sobre esses sujeitos foi de $75 \%$ do total. Uma quantidade significativa de pesquisadores tende a considerar somente os sujeitos típicos e cerca de $25 \%$ faz trabalhos comparativos entre típicos e atípicos usando grupos de controle.

Tabela 4: Sujeitos, quanto à faixa etária.

\begin{tabular}{|l|r|r|r|}
\multicolumn{1}{|c|}{ Faixa etária } & Mestr. & Dout. & Total \\
\hline Criança & 95 & 32 & 127 \\
\hline Não indicado no resumo & 1 & 0 & 1 \\
\hline Não Tem & 10 & 5 & 15 \\
\hline Adulto - Professor & 9 & 3 & 12 \\
\hline Criança e adolescente & 6 & 2 & 8 \\
\hline Adulto - Aluno EJA & 3 & 3 & 6 \\
\hline Adolescente & 3 & 0 & 3 \\
\hline Adulto - Aluno ES & 5 & 1 & 6 \\
\hline Criança e Adultos - EJA & 2 & 1 & 3 \\
\hline Adolescente e Adulto - Aluno EJA & 1 & 0 & 1 \\
\hline Adulto & 1 & 0 & 1 \\
\hline Adulto - Aluno e Professor EJA & 1 & 0 & 1 \\
\hline Adulto - Professor e crianças & 3 & 0 & 3 \\
\hline Total & 140 & 47 & 187
\end{tabular}




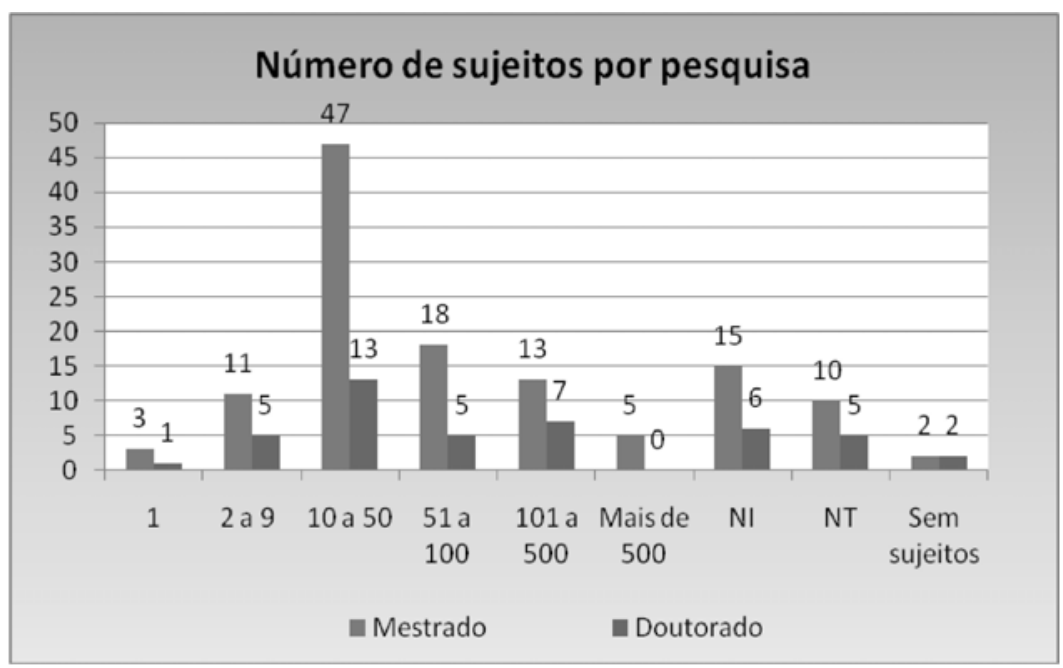

Figura 6: Número de sujeitos por pesquisa.

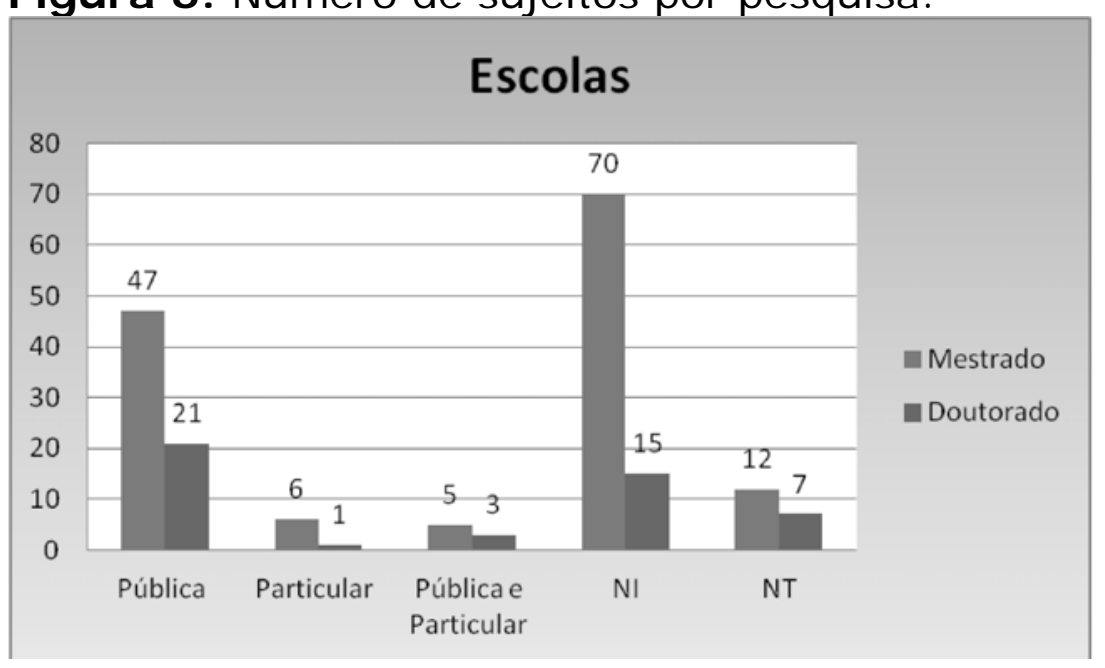

Figura 7 : Sujeitos quanto ao tipo de instituição.

Analisando em conjunto os dados apresentados (Tabela 4, Figuras 6 e 7) tem-se que as pesquisas estão focadas em crianças, dos anos escolares iniciais (principalmente alfabetização) e que a maior parte trabalhou com um total 10 a 50 sujeitos. Além disso, um número significativo de resumos não informou o dado quanto ao tipo de instituição estudada, principalmente as dissertações de mestrado.

Esses dados revelam a necessidade de ampliar as idades alvos das pesquisas, pois o aumento gradativo das mesmas, não está sendo acompanhado pela ampliação da diversidade de sujeitos quanto a tipicidade e idade e de maior detalhamento das informações sobre os estudos apresentadas nos resumos.

É esperado que a quantidade de estudos continue proporcionalmente mais concentrada nos primeiros anos do ensino obrigatório, pois se constituem as séries nas quais conhecimentos fundamentais sobre leitura e escrita precisam ser desenvolvidos, pré-condição para aquisição de vários outros conhecimentos e habilidades escolares, para seu aperfeiçoamento posterior e sobretudo para a maior 
autonomia do estudante. Ressalta-se que a persistência e redundância dos estudos sobre as habilidades metalinguísticas nestes primeiros anos de escolarização se faz necessária em termos da produção de evidências científicas e de sua ampla divulgação, capaz de impactar de modo mais enfático a produção da qualidade do ensino formal nos primeiros dois ou três anos do ensino fundamental. Por outro lado, tem-se que o desenvolvimento das habilidades metalinguísticas, como voltadas para a reflexão e manipulação de aspectos relacionados à linguagem oral, começam desde os primeiros anos de vida, no período da educação infantil. Mesmo a linguagem oral pode ser aperfeiçoada e impactar posteriormente a aprendizagem da escrita, se compreendida e trabalhada neste período. Razão pela qual se justifica que mais estudos também se dediquem a esclarecer diferentes aspectos do desenvolvimento metalinguístico nesta fase da escolarização, que antecede o processo de alfabetização.

O interesse pelo estudo das habilidades metalinguísticas em etapas mais avançadas da escolarização também se justifica, visto que a consciência ortográfica, por exemplo, continua a se aperfeiçoar até o fim da vida para escritores e eleitores ativos. Mesmo porque a língua também e dinâmica e exige atualização constante de seus usuários.

Outro dado que chama a atenção é o número reduzido de pesquisas na área da Educação de Jovens e Adultos, pois muitos são os adultos analfabetos ou analfabetos funcionais que poderiam ser beneficiados com pesquisas nessa área, por exemplo, ao subsidiar a produção de materiais educativos adequados a este público, com foco no desenvolvimento de habilidades metalinguísticas. Tais contribuições poderiam advir de estudos comparativos que acompanhassem 0 desenvolvimento de habilidades metalinguísticas em alfabetizandos na idade esperada e em jovens e adultos.

Como evidenciado na revisão de literatura, diferentes são as relações e contribuições das habilidades metalinguísticas para a aprendizagem da leitura e da escrita, sendo o inverso também verdadeiro. Os resultados dos trabalhos de dissertação e tese aqui examinados por meio de seus resumos enfatizam estas mesmas evidências, sob diferentes aspectos.

\section{Considerações Finais}

O objetivo do presente artigo foi mapear a produção acadêmica brasileira sobre desenvolvimento metalinguístico e linguagem escrita no período de 2005 a 2010, em dissertações e teses.

Assim como já constatado por Maluf, Zanella e Pagnez (2006) (2006), a produção de estudos defendidos em programas de pósgraduação no país ampliou-se fortemente nos últimos anos, o que denota a expansão da pós-graduação, bem como da formação de 
pesquisadores que passaram a formar grupos de pesquisa que vem se consolidando, ou se consolidaram, como referência na produção de conhecimento sobre diferentes aspectos das habilidades metalinguísticas, explorando suas relações com o processo de aprendizagem da leitura e da escrita, principalmente nos primeiros anos de alfabetização.

No entanto, há estados em que não se localizou programas de pósgraduação voltados para a produção de pesquisas sobre as relações entre habilidades metalinguísticas e a aprendizagem da leitura e da escrita. Estes são principalmente das regiões Norte e Centro-Oeste, onde há menor número de universidades públicas, que tradicionalmente abrigam centros de pesquisa em diferentes áreas. Tal constatação merece ser melhor investigada e compreendida em termos do investimento na qualidade do sistema de ensino obrigatório e na produção de conhecimento científico a respeito.

Observou-se que a maior parte dos programas de pós-graduação mapeados neste levantamento é de formação em psicologia, em menor quantidade em educação e fonoaudiologia. Considera-se desejável que esta temática seja mais ensinada e estudada nos referidos campos, especialmente na educação, área na qual acontece a formação do alfabetizador.

Dois aspectos importantes a se ressaltar são: a importância de dar maior visibilidade a estes estudos e de encontrar maneiras de veiculá-los em diferentes 'linguagens' para que se tornem mais acessíveis ao público não acadêmico, sobretudo para educadores e gestores de políticas públicas relacionados com alfabetização.

Neste sentido, sugere-se o maior cuidado e atenção dos pesquisadores em relação à elaboração do resumo e escolha das palavras-chave que irão representar e chamar a atenção para seus trabalhos, de modo a garantir a presença de informações fundamentais sobre a pesquisa, tais como as que foram objeto de análise no presente estudo.

Poucos estudos investigaram até o momento outras faixas etárias que não as da infância. Pode-se indagar bastante a respeito do desenvolvimento inicial dessas habilidades na educação infantil, se são preditoras de outras aquisições posteriores durante a escolarização, como já se constatou em relação ao papel preditor do desenvolvimento da consciência fonológica.

Outra questão é como essas habilidades se configuram em anos mais avançados do ensino fundamental e médio e sobre seu papel na expansão das habilidades requeridas em tarefas mais sofisticadas de leitura e escrita da língua.

Concluindo, estudos de revisão como este podem auxiliar o processo de identificação de questões relevantes e originais que podem se tornar objeto de investigação e teorização, suscitadas pelos estudos já realizados, para que "se dê um passo à frente". 


\section{Referências}

BARRERA, S. D. Papel facilitador das habilidades metalinguísticas na aquisição da linguagem escrita. In: Maria Regina Maluf. (Org.). Metalinguagem e aquisição da escrita: contribuições da pesquisa para a prática da alfabetização. São Paulo: Casa do Psicólogo, 2003., p. 65-90.

BARRERA, S. D.; MALUF, M. R. Consciência metalinguística e alfabetização: um estudo com crianças da primeira série do ensino fundamental. Psicologia: Reflexão e Crítica, Porto Alegre, v. 16, n. 3, p. 491-502, 2003.

BRASIL. Mapa do analfabetismo no Brasil. Brasília, DF: Instituto Nacional de Estudos e Pesquisas Educacionais Anísio Teixeira, 2003.

BRASIL. Sinopse do Censo Demográfico 2010. Brasília, DF: IBGE - Instituto Brasileiro de Geografia e Estatística. Disponível em: <http://www.censo2010.ibge.gov.br/sinopse/index. php?dados=P6\&u $\mathrm{f}=00>$ Acessado em 04 fev. 2012.

CAPELLINI, S. A.; CIASCA, S. M. Eficácia do programa de treinamento com a consciência fonológica em crianças com distúrbios de leitura e escrita e distúrbio de aprendizagem. Temas sobre Desenvolvimento, São Paulo, 52, n. 1, p. 4-10, 2000.

CAPOVILLA, A.G.S.; CAPOVILLA, F.C. Efeitos do treino de consciência fonológica em crianças com baixo nível socioeconômico. Psicologia: Reflexão e Crítica, Porto Alegre, v. 13, n. 1, p. 7-24, 2000.

CARDOSO-MARTINS, C. (Org.). Consciência fonológica e alfabetização. Petrópolis: Vozes, 1995.

CARDOSO-MARTINS, C.; BATISTA, A.C. E. O conhecimento do nome das letras e o desenvolvimento da escrita: Evidência de crianças falantes do português. Psicologia: Reflexão \& Crítica, Porto Alegre , v. 18, n. 3, p. 330-336, 2005.

CARDOSO-MARTINS, C.; SILVA, J. R. A relação entre o processamento fonológico e a habilidade de leitura: evidência da síndrome de Down e da sídrome de Williams. Psicologia: Reflexão e Crítica, Porto Alegre, v. 21, n. 1, p. 83-90, 2008.

CARLISLE, J. Morphological Awareness and Early Reading Achievement. Em L. B. Feldman (Org.). Morphological aspects of language processing. Hillsdale, NJ: Lawrence Erlbaum Associates, 1995. p. 189-209.

CHIARINI, T.; VIEIRA, K. P.; ZORZIN, P. G. Universidades federais mineiras: análise da produção de pesquisa científica e conhecimento no contexto do sistema mineiro de inovação. Nova economia, Belo Horizonte, v. 22, n. 2, $2012 . \quad$ Disponível em: <http: //www.scielo.br/scielo.php?script=sci_arttext\&pid=S010363512012000200004\&lng=en\&nrm=iso>. Acesso em 23 jun 2013. 
CORREA, J. A avaliação da consciência morfossintática na criança. Psicologia: Reflexão e Crítica, Porto Alegre, v. 18, n. 1, p. 91-97, 2005.

CORREA, M. F., CARDOSO-MARTINS, C.; RODRIGUES, L. A. O Conhecimento do nome das letras e a sua relação com o desenvolvimento da escrita: evidência de adultos iletrados. Psicologia: Reflexão e Crítica, Porto Alegre, v. 23, n. 1, p. 161165, 2010.

DEACON, S.; KIRBY, J. Morphological awareness: just "more phonological"? The roles of morphological and phonological awareness in reading development. Applied Psycholinguistics, Halifax , n. 25, v. 2 , p. 223-238, 2004.

GOMBERT, J.-E. Atividades Metalinguísticas e Aprendizagem da leitura. In: Maluf, M.R. (Org.) Metalinguagem e aquisição da escrita: contribuições da pesquisa para a prática da alfabetização. São Paulo: Casa do Psicólogo, 2003.

GOMBERT, J.-E. Le développement métalinguistique. Paris: PUF, 1990.

GUIMARÃES, S. R. K.; PAULA, F. V. de. O papel da consciência morfossintática na aquisição e no aperfeiçoamento da leitura e da escrita. Educar em Revista, Curitiba, v. 38, n. 1, p. 93-111, 2010.

HAGEN, V.; MIRANDA, L. C.; MOTA, M. M. P. E. da. Consciência morfológica: um panorama da produção científica em línguas alfabéticas. Psicologia: Teoria em Prática, Brasília , v. 12, n. 3, p. 135-148, 2010.

HERRIMAN, M. L. Metalinguistic awareness and the growth of literacy. In: S. Castell, A. Luke e K. Egan (Orgs.). Literacy, society and schooling. Cambridge: Cambridge University Press, 1986. p. 159174

HUTZ, C. S.; ROCHA, M. L. da; SPINK, M. J. S.; MENANDRO, P. R. M. Perfil, avaliação e metas de produção intelectual dos Programas de Pós-Graduação em Psicologia. Psicologia: Reflexão e Crítica, Porto Alegre, v. 23, supl. 1, 2010. Disponível em: <http: //www.scielo.br/scielo.php?script=sci_arttext\&pid=S0102-

$79722010000400004 \& \mid n g=p t \& n r m=i s o>$ Acesso em 10 de agosto 2012.

MALUF, M. R.; BARRERA, S. D. Consciência fonológica e linguagem escrita em pré-escolares. Psicologia: Reflexão e Crítica, Porto Alegre, v. 10, n. 1, p. 125-145, 1997.

MALUF, M. R.; ZANELLA, M. S.; PAGNEZ, K. S. M. M. Habilidades metalinguísticas e linguagem escrita nas pesquisas brasileiras. Boletim de Psicologia, São Paulo, v. 56, n. 124, p. 67-92, 2006. MOTA, M. M. P. E (Org.). Desenvolvimento Metalinguístico: Questões Contemporâneas. 1. ed. São Paulo: Casa do Psicólogo, 2009. 
NESDALE, A. R.; TUNMER, W. E. The development of metalinguistic awareness: A methodological overview. In: W. E. Tunmer, C. Pratt e M. L. Herriman (Orgs.). Metalinguistic awareness in children: Theory, research and implications. New York: Springer-Verlag, 1984. p. 36-54

PAULA, F. V.; CORREA, J.; SPINILLO, A. G. O conhecimento metalinguístico de crianças: o papel das aprendizagens implícitas e explícitas. In: M. A. L. e Dias, K. O. Fukumitsu e A.F.T. Melo (Orgs.). Temas Contemporâneos em Psicologia do Desenvolvimento. São Paulo: Vetor, 2012. p. 161-196

SALLES, J. F.; JOU, G. I.; STEIN, L. M. O paradigma de priming semântico na investigação do processamento de leitura de palavras. I nteração em Psicologia Curitiba, V. 11, n. 1, p. 71-80, 2007.

SEVERINO, A. J. PÓS-GRADUAÇÃO E PESQUISA: o processo de produção e de sistematização do conhecimento. Revista Diálogo Educacional, Curitiba ,v. 9, n. 26, p. 13-27, 2009.

SPINILLO, A. G.; SIMÕES, P. O desenvolvimento da consciência metatextual em crianças: Questões conceituais, metodológicas e resultados de pesquisas. Psicologia: Reflexão e Crítica, Porto Alegre, n.16, v.3, p. 537-546, 2003.

\section{Endereço para correspondência}

Ellen Michelle Barbosa de Moura

Escola 831 de Samambaia, QR 831, Conjunto 1, lote 01, CEP 72338-711, Brasília, Distrito Federal

Endereço eletrônico: ellencrasamambaia@gmail.com

Fraulein Vidigal de Paula

Universidade de São Paulo

Av: Prof. Mello de Morais, 1721, sala 188, CEP 05508-030, São Paulo, Brasil

Endereço eletrônico: fraulein@usp.br

Recebido em: 21/08/2012

Reformulado em: 28/06/2013

Aceito para publicação em: 02/07/2013

Acompanhamento do processo editorial: Adriana Benevides Soares

\section{Notas}

* Secretaria de Educação do Distrito Federal Brasília - Brasil; Mestre em Educação

** Doutora em Psicologia. Professora do Instituto de Psicologia da Universidade de São Paulo, USP. 